\title{
Journalism in minefields: extreme practices in AIDS environment in Cameroon
}

\begin{abstract}
This article examines how journalism has been reconfigured by social demand communication imposed by the context of AIDS in Cameroon. It shows in particular how the discourse of the institutions involved in the response against the disease have invested the public space by producing a discourse whose lexicon has gradually established itself as an event processing with standard journalistic reception highlighted the relationship between socio-cultural practice settings of the profession and the doctrinal injunctions set by professional journalism notables. Taking account of how the AIDS enrolled in space debates at national level, it also reveals the challenges of universal principles of the response in a context where health and medical practices and rules journalistic discipline is never the product of socially constructed accommodation.
\end{abstract}

Keywords: journalism, communication, stress, AIDS, discourse, socially, journalistic, political
Volume 2 Issue 6 - 2018

\section{Laurent Charles Boyomo Assala, Marie Marcelle Mpessa Mouangue}

Department of Communication and Civilization, University of Yaounde 2 Cameroon

\author{
Correspondence: Laurent Charles Boyomo Assala, \\ Department of Communication and Civilization, Professor \\ ESSTIC- University of yaounde 2, Cameroon, \\ Email cboyamo@yahoo.fr
}

Received: October 22, 2018 | Published: November 21, 2018

\section{Introduction}

Member states of the United Nations adopted June 8, 2016 the new Political Declaration on HIV/AIDS, printing an orientation that paradoxically marked the end of the epidemic. Despite the appeal of more than 50 associations of civil society, the final declaration of the "High Level Meeting" on HIV/AIDS confirms access to treatment for 30 million people by 2030 , certainly, but back on the inclusion of people say the most exposed to the virus and new infections today, namely men who have sex with men, injecting drug users, sex workers and transsexual (them). Member states have not agreed among other concrete targets for accelerating access to rights, services and funding for key populations. This slowdown in the global response against AIDS is to be related to the loss of media interest especially journalists with regard to this scourge, loss of interest, the gradual disappearance of the AIDS subject in journalism media testifies decisively. This media shortness raises also the problem of media life expectancy of a social problem whose disappearance in the public space does not necessarily imply the resolution. If one believes the figures, 30 million people remain infected worldwide have become the unthought communication programs and the blind spot of journalism. The media coverage of these new issues in the public space by media devices that no longer depend on journalists, and the emergence of media communication devices raise new questions about the new forms of public expression through the internet and in particular their impact on the practices of journalism in contact with these forms of extending its scope. How journalistic practices which in recent years have moved towards societal issues to be better in significance with the public space and will operate if one believes Ruellan "permanent equity adjustment" in terms of development strategies, were tested and held in tension? The question of what is the fate of societal journalism becomes more complex benefit in the context of extreme social fragility of HIV/AIDS.

What was and what is the impact of AIDS on the field of journalism in Cameroon? It is clear to this general question attempts to answer this contribution. In the media, AIDS is made present through the discourse of international organizations and their advisors, international intervention projects and programs and government and more indirectly through forms of coded speech, standardized and controlled medical legitimation instances. Considered from the standpoint of AIDS discourse has had a dual effect of deconstruction/ construction cross fragmentation: firstly, it has led to a discursive formation soft, difficult to consider for a traceable standard: hard journalistic productions or media literature outcome of pharmaceutical leaflets and research laboratories brochures, posters associations, scientific reports, conference proceedings, fundamental or applied work, many speeches characterize this aspect; and secondly from the perspective of professional initiative productions journalists themselves, he was successful in journalistic genres often poorly adapted to the object, contradictory or even incomprehensible. While controversy about its existence and its origins are largely faded today as a result of research findings, the great moral principles qu'affichent the AIDS discourse such as medical confidentiality, integrity sick and the right to privacy, barely conceal the complex relationships that they still maintain with journalistic practices and political and economic interests of AIDS within and outside the journalism field. Even today, we can say that AIDS remains a journalistic activity in permanent tension and, from the perspective of social accountability sometimes reinforces and sometimes weakens the autonomy of people affected and infected he hesitates to ensure either the media on the pretext of preserving their right to privacy; then either bear against socialexample, under the banner of the precautionary principle. we can say that AIDS remains a journalistic activity in permanent tension and, from the perspective of social accountability sometimes reinforces and sometimes weakens the autonomy of people affected and infected he hesitates to ensure either the media on the pretext of preserve their right to privacy; then either bear against social-example, under the banner of the precautionary principle. we can say that AIDS remains a journalistic activity in permanent tension and, from the perspective of social accountability sometimes reinforces and sometimes weakens the autonomy of people affected and infected he hesitates to ensure either the media on the pretext of preserve their right to privacy; 
then either bear against social-example, under the banner of the precautionary principle.

In this respect, it is possible to ask the question in the relationships between the worlds of journalism and communication with the disease in Africa than elsewhere analysis can she overcome mutual feelings of fascination, hostility and desire between the two worlds, as reflected in many traffic movements between the two fields? These feelings do they in turn influence the ways of working and imaginary invested in the work of journalism and communication about the disease? Moreover, they are not at the origin of migration and more or less durable passages between the two fields and that emphasize the dynamic professional while confirming instability characterized by the opportunity situations. Would we as AIDS journalism is a cultural journalism? What knowledge we provide these relationships spaces induced by the report to the disease, HIV and care?

Beyond these issues, we intend to grasp the many ways by which AIDS has influenced, pushed, challenged the norms and professional standards affected journalism and whose confused and current tendency to view media and journalism as twins, "twin organs" was the most affected. As the field of expression of competing powers, effect and normative framework speech broadcast with and supported by institutions, experts and multiple resources, land of more articulated on the international, national and local, AIDS produced its greatest impact on journalism by breaking the ontological and theoretical link between media and journalism, between journalism and communication, making multiple media discourse of media professionals and laymen, Firstly ; and journalism activity whose media testifies and serves as a locomotive to a composite hitch where cross journalistic practices revised by communicational presuppositions. Even today, a large number of paradoxes and many tensions that marked its emergence in Africa remains the most tangible index mark of the media-journalistic existence of AIDS.

We then look at how the media system is disrupted or deconstructed by AIDS and the fate that it is subjected to journalism. The paradigm of media vulnerability allows us here to capture both the context that favored the emergence of professional dissent, the emergence of communication in the argument of the social demand and efficiency of media repression under the effect of an order of discourse monitored by medical institutions, competing political and professional. Issues of trust and information legitimation process characterized by the principle of monitoring and oblique appropriations journalists have resulted. We had uses two standard methods: the first based on the combined materials discourse analysis to the analysis of content in what we mean by "body condition", that is to say a "dynamic construction corpus mobile managed interacting with the progress of analysis. To do this, we have established two types of material: first a corpus of daily newspapers (Cameroon Tribune, The Messenger, The Day and Changes) composed of 160 selected issues on the period from 2008 to 2016, taking into account that from 1986 to 2008, it is not possible to have access to newspapers, mutations that have been created 20 years later in 2000. Day 20 numbers were selected a year. Then the semi-structured interviews with a dozen journalists said daily, mainly editors and managers of health topics when there was to better understand the editorial reorganization and professional emergency reconstructions that were performed in the newspapers. Finally, direct observation of the working methods within editorial. Although not having made use of specific algorithms, we considered our documents as belonging to a memory array, a "dictionary discursive" that incorporates the effect continuously openings, reconfigurations, status changes while the corpus throughout the analysis. We know that this type of material is supported on multiple ways of speaking, enrolling themselves in a set without border where outside interdiscourse, broke into the intradiscours. The notions of interdiscourse and intradiscours allow us to question the relationships between institutional discourse on AIDS with themselves and with the outside world. The outlook is even more interesting than we have seen how a history of the disease is impossible without a visit to an institutional historiography, that is to say an operation that constantly questions the historical method which are subject data and questioned documents and the type of questions which they are subject. If indeed the speech worthy of study as they acknowledge or ignore, attract or repel, ${ }^{1}$ must still agree on the method and type of operations which we propose to submit. Krieg-Planque offers us in the wake of the work on "the policy of the languages' of the ENS, a set of highly suggestive tools for analyzing institutional discourse, which it says use. We're inspired the rest above. Concretely, media production, they come Journalists (identified by their signatures) or directly reported institutional discourse (press more or less rewritten press by members of the editorial, position) or indirectly (interviews issues -Responses or written) are in parallel with scientific contributions from medical journals and speeches of journalists held in interviews with standardized questionnaires or unstructured. These contributions under our method of what Foucault called discursive formations, that is to say, highlighting the classroom discourse and discursive stability issues inherited from the concept of forms of language. The latter is based on the assumption that the discursive boundaries are not assignable.

\section{Short history of the disease and AIDS in Africa}

Without going back too far in time, it is interesting for anyone who intends to observe how the disease is in the historic concrete of Africa, to address some aspects quite illustrative in this regard. This historical perspective to better understand the meaning of the controversies surrounding the arrival of AIDS in the African context, and scientific and socio-cultural changes that have resulted. As noted by John Paul Babo " "the institutions likely to contribute to research on the history of health in Africa, are occupied with other priorities." It is interesting in this regard to point out the slow evolution of medical concepts related to Africa, especially regarding the amarilose and Malaria to understand the socioeconomic issues that structure. Although rare, historical works and / or biomedical origin provide an interesting bibliography on knowledge of the disease and can track the change designs and denominations of diseases in the African context. First this: "Politically, written Babo, In colonial times, all medical issues had political implications. For example, policies and health priorities reasons, the health authorities of the French West Africa remained insensitive to the alarm call of Dr. Paul Gouzien to save the region from the Black Volta (Mouhoun) decimated by human trypanosomiasis. For political reasons also, the leaders of the Oubangui-Chari and French Equatorial Africa supported by the Ministry of settlements prevented the publication in 1919 of a report on Jamot trypaniques havoc in Ubangi-Shari."

It is appropriate at this point to return to two conductor's son that structure our analysis of the public debate implementation of AIDS and its role in the communicative tensioning. The first wire is carried by the question of immunity of blacks that divided both the medical profession in the nineteenth century. Firstly, the entry into medicine in Africa took place under the illusion of immunity Blacks, before 
turning into spontaneous anthropological explanations and Darwinian inspiration. At the end of the nineteenth century and especially after the discovery of antimalarial antibodies in 1899 in Saint Louis, Senegal by the doctor Émile Marchoux in children and in the military traveling in other regions, the absence of disease manifestations among blacks compared with Europeans, "The natural immunity of certain tribes inhabiting the marsh areas, obviously due to natural selection set for generations. Many children die in the first years of their lives, those who are more likely resist and procreate themselves a tough race ", emphasizes parasitologist Émile Brumpt in 1910. Until the identification of mosquito stégomia fasciata (yellow fever vector), the medical profession remained divided however on the immunity of blacks to the point that, with regard to malaria, a royal commission appointed by the British government in 1826 reported a year later in 1795 in Sierra Leone, $46 \%$ of European settlers them died of malaria, and $39 \%$ of "black poor" brought back from London, according to Curtin $^{3}$ breaking the taboo of immunity Black.

The controversy surrounding the political fight against trypanosomiasis and malaria illustrates in this respect how they have moved towards the second, although less harmful than the first. "In one we see only the image of the terrible skeleton mask; the other, certainly worse decimated and continues to ravage in the silence of generations of children ... The work of Jamot situated himself in the period of colonialism triumphant with its law on the rights of citizenship. In contrast, contemporary this time, Schweitzer does not benefit from the same advantages because of its status and suspicions against him because of his family ties with Germany." Regarding the development of AIDS in Africa, the warning has initially focused on the temptation to yield to researchers spectacular, the illusion of novelty, sometimes giving guidance on the continent, considering them as personal viewpoints. Favoring as did Mirko Grmek example in history of $\operatorname{AIDS}^{3}$ what he called "promiscuity" as risk factor in Africa is yielding to the laziness of the anthropological alibi. As finely questions Babo, "It would be interesting to know what the author meant by sexual promiscuity. The rise of syphilis-Quetel, Evil Naples $^{4}$ and other sexually transmitted diseases it would depend on sexual promiscuity? This term promiscuity reminds unintentionally, the definition by evolutionists of the nineteenth century, the first stage of unregulated sexual activity. We can only emphasize that Africa through the concentration of different ethnic groups subject to other rules of life than theirs; urbanization upset the pre-existing relationship before sexual relationship".

The second common thread is on the cultural approach which raises the specific problem of permanence and ruptures. First of all, want to enclose a disease in the vision that gives it an ethnic group or in reference to the values of the person who studies is insufficient. In this sense, the approach by changing attitudes advocated by health communication strategies deserves special attention. Since independence, the migration has accelerated. Many ethnic groups have seen their membership temporarily or permanently immigrate to town to give birth to the first generation of true citizens. Today there is in the second or even third generation of city dwellers. Although delicate, the study of cultural changes-permanence and ruptures-can show the huge effort to be made by modern medicine, despite success. Too often, external structures, "Surface tub" hide stability and sometimes stagnating deep behaviors. Although we do not build our ayions research object around this concern, it illuminates our analysis in two complementary ways. First, the fact, as many anthropologists notice, that many Africans are changing between two logics, two sensibilities and leave themselves coexist duality, that is to say the need for permanence traditions and some ancestral mentality and willingness to break with this past ancestral to overcome it. The practices of going from doctor to doctor to get effective care existed for centuries. Babo reports that during their visit in the second half of the nineteenth century in West Africa Henri Barth explorers ${ }^{5}$ signaled them. Sun Delobsomm in the current Burkina Faso, Plowing in the former French West Africa, and in the former Vergiat Ubangi-Shari (now Central African Republic) confirm the existence of such practices in the 1930 Colonial arrested to punish specialists the empirical and metaphysical medicine also prove their magnitude. The weaknesses of modern medicine often helpless regarding therapeutics, poorly equipped by default credits explain the extent of the therapeutic itineraries. How then do not understand the disappointment of those who contract smallpox despite the supposed vaccine received immunize? How could they accept the identification of people with firsthand any signs of disease, as healthy-carriers of a disease, the moment they had and have their own semiotics? The same questions can be asked today for AIDS positive people with whom we do not see outward signs of the disease. The principle of magic shield, which could have inspired colonial doctors to convince people of the benefit of the vaccine, has not attracted the attention of modern doctors. Indeed, from the perspective of African societies the magic shield aims to capture supernatural forces to form an impenetrable barrier between humans and disease. In drawing a parallel between the objective of magic shield and the vaccine, people would be better accepted failures of vaccination in their designs since the magical armor can give way under the power of the aggressor. With the success hundred percent, vis-à-vis distrust of the vaccine would be gone. Knowledge of the nature and context of AIDS should benefit from anthropological and sociological work, but also those from demographics and focus on African societies. It should be also taken into account, "Needless to say, the need to replace the diseases and medicines in their biological, social and cultural context, to consider the changes in order not to freeze companies, and especially to avoid" collisions historical periods".

Next, a gap can be observed in the scientific and social concerns of the disease: if indeed we recognize that overall academic discourse on AIDS, anthropology occupies a central place due to the nature same disease, which affects not only the individual life and that of others and beyond questioning the survival of all humanity like some other epidemics; but also because it touches on what is the essence of human nature, namely, sexuality and identity of the individual in relation to its symbolic representation. If anthropological knowledge is inseparable from knowledge of the disease and leads us to ask, beyond the academic discipline and one of its leading figures whose work helped establish AIDS as a subject of anthropological study namely Francoise Heritier, all the speeches with an interest in the being and the human condition in its report to the disease, this position does not hide the existence of alternative discourses and ordinary laymen and its implementation in conflict with scholarly discourse themselves opposed to each other across disciplines and within the same subjects; Even today the agreement is far from being found. This position does not hide the existence of alternative discourses and ordinary laymen and its implementation in conflict with scholarly discourse themselves opposed to each other across disciplines and within the same disciplines; even today the agreement is far from being found. This position does not hide the existence of alternative discourses and ordinary laymen and its implementation in conflict 
with scholarly discourse themselves opposed to each other across disciplines and within the same disciplines; even today the agreement is far from being found.

\section{Results}

Examination of the configuration of the tensioning of journalism or its setting in abyss, is instructive in that it asks three communicative action territories: the pop territory as part of a supposed historical concrete reflect the actual principle which journalists believe and translate it into a historiography that is special to them; the territory of institutional powers, both political (state, international organizations), professionals (both from the middle of medicine, medicine and journalism and civil society), that of sufferers (they $\mathrm{s}$ 'express directly or through "spokesman"). Finally the media territory it takes into account the written production in the newspapers or he falls statements and journalistic positions. At the international institutional level, many countries have put in place since the 70 major campaigns of media communication in the field of health. These campaigns have reached their peak with the outbreak of AIDS, which has led to explore the theories depend on research into the disease. Psychosocial theories have gained in these studies a strategic position because of the interest in the campaign targets from their attitudes, expectations, intentions and their ability to integrate into the campaign objectives. Thus media communications have become an "indispensable strategy in health promotion," according to Bouchard ${ }^{6}$ It is expected of them effective awareness of individual target markets, organizational and community. They must foster in them the acquisition of knowledge, changing attitudes and healthy behaviors. A social and scientific consensus seems to have emerged as the need of communication in public health, causing it to identify its strengths and limitations. In particular, depending on they must foster in them the acquisition of knowledge, changing attitudes and healthy behaviors. A social and scientific consensus seems to have emerged as the need of communication in public health, causing it to identify its strengths and limitations. In particular, depending on they must foster in them the acquisition of knowledge, changing attitudes and healthy behaviors. A social and scientific consensus seems to have emerged as the need of communication in public health, causing it to identify its strengths and limitations. In particular, depending on ${ }^{7}$ the use of media is more effective if the following principles are respected: the message arouses the audience's personal commitment or motivation to change; the message is repeated several times (overkill) through different media and sources, and for a long period of time (years, not weeks and months); the message is "new" or "entertaining" and managed to keep the attention and arouse the audience's interest; the message shows specific results and offers a range of behaviors or situations acceptable to the audience, that are compatible with the design of health and are also compliant. The strategies are however complementary. They are elaborated in a interdiscourse that combines health education, community organizing, political action, the organizational development and change, and media communication, to their success. They are part of the global policy of health promotion hinged on universalizing standards. The said policy helps to highlight the different levels of understanding of the communicative issue, in connection with the problematic situation: the information level, first, considered a good or service to be perceived, understood, integrated and shared by individuals in their surroundings; the media level that allows disseminates information through its (posters, newspaper articles, radio and television programs, etc.), but must be part of the differential value of the wide dissemination of communication (television, radio, print, internet) and restricted (brochures, videos, posters). The binding of the health goal (lifestyle, access to care and services) with the communication objective (awareness, knowledge, attitudes, and behavior) is also an essential condition for implementation of the strategy. However the approach of participatory communication as standard has its limitations regarding AIDS.

In Cameroon, it was in 1985 that AIDS appears officially, with 21 cases reported by the National Program in place to cope. Between 1985 and 2000, more than 34,000 cumulative cases will be identified and Seroprevalence during the same period has increased steadily until 2010. Since 2011, however, a decline began with the combined efforts of powers public, international and national NGOs organizations to the point that, according to the survey of demography and health in 2011, the prevalence of admitted VID is $4.3 \%$ against 5.5\% in 2004 . The number of new infections in the general population is meanwhile estimated at 58,630, which represents an average of 161 infections per day, or about 7 new infections every hour. Half of the new infections $(54 \%)$ are children under 5 years $(15 \%)$, young people from 20 to 29 years $(39 \%)$ as women form the most affected by the infection groups. They are the priority target groups identified following the UNGASS indicators (United Nations General Assembly Special Session). Two other targets are covered by the programs, namely, vulnerable and mobile populations (Pygmies, Bororo, refugees, internally displaced people, fishermen) with varying seropositivity (2.5\% among pygmies); and groups with risk behaviors (truck drivers, sex workers estimated at 20145 people around Cameroon and a prevalence rate of $36.8 \%$ in 2009 MSM -men who have sex with men - defense and security forces with a prevalence of $11.2 \%$ of the prison population with a prevalence of $8 \%$ more exposed to the HIV/TB co-infection). From 1987 to 2000, various emergency plan have been implemented with varying degrees of success. In particular, a number of problems have hindered the effectiveness of the national response are: insufficient coordination among the various stakeholders and program partners; a lack of resources allocated to the program coupled with insufficient involvement of sectors other than health in prevention activities; a significant increase in the number of infected people in the skilled population initially "not at risk". Populations prison with a prevalence of $8 \%$ more exposed to the HIV/TB co-infection). From 1987 to 2000, various emergency plans have been implemented with varying degrees of success. In particular, a number of problems have hindered the effectiveness of the national response are: insufficient coordination among the various stakeholders and program partners; a lack of resources allocated to the program coupled with insufficient involvement of sectors other than health in prevention activities; a significant increase in the number of infected people in the skilled population initially "not at risk". Populations prison with a prevalence of $8 \%$ more exposed to the HIV/TB co-infection). From 1987 to 2000, various emergency plan have been implemented with varying degrees of success. In particular, a number of problems have hindered the effectiveness of the national response are: insufficient coordination among the various stakeholders and program partners; a lack of resources allocated to the program coupled with insufficient involvement of sectors other than health in prevention activities; a significant increase in the number of infected people in the skilled population initially "not at risk". a set of problems have hindered the effectiveness of the national response are: insufficient coordination among the various stakeholders and program partners; a lack of resources allocated to the program coupled with 
insufficient involvement of sectors other than health in prevention activities; a significant increase in the number of infected people in the skilled population initially "not at risk". a set of problems have hindered the effectiveness of the national response are: insufficient coordination among the various stakeholders and program partners; a lack of resources allocated to the program coupled with insufficient involvement of sectors other than health in prevention activities; a significant increase in the number of infected people in the skilled population initially "not at risk".

The HIV prevalence rose from $0.5 \%$ in 1987 to $7.2 \%$ in 1998 in the overall population. Cameroon will adopt in this regard four national strategic plans against AIDS: September 12, 2000, the Government launched the first strategic plan developed and implemented by the national fight against AIDS Committee (NAC). Integrated in the National Program (NACP), the strategic plan is to improve the living conditions of Cameroonians following different wage cuts and devaluation of the CFA franc in early 1990. It should also allow maintain national Seroprevalence below the critical threshold of $10 \%$. The NSP 2000-2005 key ideas concern the decentralization of activities to the health district, with administrative as common operational unit. Its strategic priorities are based on a precise inventory composed as follows: political factors deemed favorable to the fight against HIV / AIDS, the dynamism of the engagement of civil society, the predominance of preventive actions, a significant potential of the players in the fight; an increased Seroprevalence and sick among youth, women, men in uniform, truck drivers and prostitutes. The goals were for their particular bring Cameroonians from 5 to 14 years to adopt a healthy lifestyle in a context marked by the epidemic, with adult sexual behaviors safer and Cameroonian society to foundations solidarity to support people living with HIV and AIDS. The second Strategic Plan 2006-2010 included meanwhile six areas including universal access to prevention, that of adults and children infected treatment, protection and support for orphans and vulnerable children (OVC), ownership of the fight by all stakeholders, promotion of research and epidemiological surveillance and strengthening decentralization and coordination, partnership and monitoring and evaluation. The latest 2011-2015 strategic plan was adopted in 2010 around some new principles:

a) The application of the principle of the "Three Ones" and the Paris Declaration aimed at strengthening national coordination mechanisms and develop dialogue with partners to strengthen ownership, alignment, harmonization, results-based management and mutual accountability

b) The strengthening leadership at all levels

c) Increased 'implication PHAs and targeting of interventions

d) The integration of cross-cutting issues (gender, human rights and equity)

e) The planning, management and budgeting results-oriented

f) The good governance and respect for the environment

g) The fourth strategic plan extending from 2014 to 2017

Its main objective to review the progress of the NSP 2011-2015 to identify the main obstacles to the achievement of objectives and propose solutions readjustment. It is based on a mid-term analysis of the results of the previous plan and focuses on prose care including treatment and prevention of new infections. Registration of development of the various strategic planning process in a participatory policy approach as advocated by WHO, called for a communicative dimension of public consultation and would need to consider the terms of agreement in the public area of health under which they were made. Now as part of this approach, it should take into account that a large number of groups not involved in the training areas consist of collective viewpoints (Parliament, municipal councils, tontine, unions, friends, etc); secondly, the essentially exogenous origin of the historical response and the nature of pandemics are an obstacle to civic dynamics and of inequality in access to the public debate on AIDS. Public debates are themselves crossed by a lasting tension between an opinion which regarded AIDS as a new form of colonial rule even more burdensome she associated with health, economic domination, political and cultural life of the West Africa on the one hand; and expert circles of all kinds often taken aback by the rapid spread of the disease, on the other. But otherwise, equal participation does not mean equality of influence, debates on AIDS have set many discursive logic of confrontation whose access to public space resources were as unequal as were the arguments of the participants. The special position of the media and journalists in the AIDS field is a relevant input to examine the theoretical frameworks of communication and mobilized to build on each other's contributions to building a comprehensive approach to global dynamics. These dynamic, you know, put in competition with the professional standards of health and communication and media discourse structuring process and journalistic approaches and health as well as their terms of enactment. At scientific and although there are no comprehensive studies, we can consider with Tatiana Mossus ${ }^{8}$ between 1986 and 2014, 810 publications identified through the search engine PubMed have addressed the question of AIDS from the Cameroonian medical, 229 journals in which 16 were documenting the greatest number of publications (p. 138). Some of these magazines had a high strategic impact factor (impact of the knowledge contained in research on the development of the strategy and determined by the number of recommendations for a given period). The literature review has shown and the number of articles published was inversely proportional to the impact factor. So, if the journal Aids Res Hum Retroviruses gathers the largest number of articles of Cameroon (60 per study period, or $8.47 \%$ of total articles), its impact factor is 2.325 only. In comparison, the Lancet, who garnered only 8 "Cameroonian" publications for the same period, has an impact factor of 45.217. During the study period, the number of scientific articles Cameroon has continued to grow from 2 to 60 with a top 71 in 2013 and a slump in 1987 (01article). Similarly, the search seemed very self-oriented, since the entities are having done their research were predominantly Cameroon $(36.6 \%$ of publications, mainly university) some of these texts aligning between 6 and 10 Cameroonian authors (47\%). The research interests were extremely varied and showed a rise in general: the coordination of the fight, diagnosis, target groups, traditional medicine (very poorly represented) and prevention, blood transfusion, epidemiological surveillance, promoting research, prevention of transmission from mother/child transmission (PMTCT). Issues such as basic research (142 articles), co-infection and opportunistic diseases (139articles), support (132articles), and prevention (97items) concern advantage that other researchers listed issues. On the internet, only 235 texts $(45.9 \%)$ of the publications were consulted either in full text or after a free subscription. the coordination of the fight, diagnosis, target groups, traditional medicine (very poorly represented) and prevention, blood transfusion, epidemiological surveillance, promotion of research, prevention of transmission from mother/child transmission 
(PMTCT) . Issues such as basic research (142articles), co-infection and opportunistic diseases (139articles), support (132articles), and prevention (97items) concern advantage that other researchers listed issues. On the internet, only 235 texts $(45.9 \%)$ of the publications were consulted either in full text or after a free subscription. the coordination of the fight, diagnosis, target groups, traditional medicine (very poorly represented) and prevention, blood transfusion, epidemiological surveillance, promotion of research, prevention of transmission from mother/child transmission (PMTCT) . Issues such as basic research (142articles), co-infection and opportunistic diseases (139articles), support (132articles), and prevention (97items) concern advantage that other researchers listed issues. On the internet, only 235 texts (45.9\%) of the publications were consulted either in full text or after a free subscription. epidemiological surveillance, the promotion of research, prevention of transmission from mother/child transmission (PMTCT). Issues such as basic research (142articles), co-infection and opportunistic diseases (139articles), support (132articles), and prevention (97items) concern advantage that other researchers listed issues. On the internet, only 235 texts $(45.9 \%)$ of the publications were consulted either in full text or after a free subscription. epidemiological surveillance, the promotion of research, prevention of transmission from mother/child transmission (PMTCT). Issues such as basic research (142 articles), co-infection and opportunistic diseases (139articles), support (132articles), and prevention (97 items) concern advantage that other researchers listed issues. On the internet, only 235 texts (45.9\%) of the publications were consulted either in full text or after a free subscription. and prevention (97 items) worrying benefit researchers as other issues identified. On the internet, only 235 texts $(45.9 \%)$ of the publications were consulted either in full text or after a free subscription. and prevention (97 items) worrying benefit researchers as other issues identified. On the internet, only 235 texts $(45.9 \%)$ of the publications were consulted either in full text or after a free subscription.

From the point of view of the media and configuration of media content more precisely the orientation was different. First, it was necessary to inform the international community and through the media arena as the guidelines of the World Health Organization are being implemented in the country; the infection is considered a public health problem of great importance for the absorption of the problem for which the government also is seeking the support of this community. The presentation of the activities of the national program against AIDS covered for its two communication aspects during this period: the first focused on the development of prevention messages, the second concerned the prevention of this infection in hospital media constituting both platforms and players of activities. The radio campaign, made commercials at the beginning and at the end of each edition of the news bulletins, involved fifty messages developed by the Health Education Department of the Ministry of Public Health. This campaign hinging on the following communication areas: AIDS kills regardless of how we contract it; it is the disease of "risk groups", that is to say, prostitutes, drug addicts, homosexuals; some practical tips to prevent AIDS, particularly in contacts with people; awareness about the basic precautions to take in case of accidental contact with those infected. The radio campaign, made commercials at the beginning and at the end of each edition of the news bulletins, involved fifty messages developed by the Health Education Department of the Ministry of Public Health. This campaign hinging on the following communication areas: AIDS kills regardless of how we contract it; it is the disease of "risk groups", that is to say, prostitutes, drug addicts, homosexuals; some practical tips to prevent AIDS, particularly in contacts with people; awareness about the basic precautions to take in case of accidental contact with those infected. The radio campaign, made commercials at the beginning and at the end of each edition of the news bulletins, involved fifty messages developed by the Health Education Department of the Ministry of Public Health. This campaign hinging on the following communication areas: AIDS kills regardless of how we contract it; it is the disease of "risk groups", that is to say, prostitutes, drug addicts, homosexuals; some practical tips to prevent AIDS, particularly in contacts with people; awareness about the basic precautions to take in case of accidental contact with those infected was about fifty messages developed by the Health Education Department of the Ministry of Public Health. This campaign hinging on the following communication areas: AIDS kills regardless of how we contract it; it is the disease of "risk groups", that is to say, prostitutes, drug addicts, homosexuals; some practical tips to prevent AIDS, particularly in contacts with people; awareness about the basic precautions to take in case of accidental contact with those infected was about fifty messages developed by the Health Education Department of the Ministry of Public Health. This campaign hinging on the following communication areas: AIDS kills regardless of how we contract it; it is the disease of "risk groups", that is to say, prostitutes, drug addicts, homosexuals; some practical tips to prevent AIDS, particularly in contacts with people; awareness about the basic precautions to take in case of accidental contact with those infected that is to say, prostitutes, drug addicts, homosexuals; some practical tips to prevent AIDS, particularly in contacts with people; awareness about the basic precautions to take in case of accidental contact with those infected that is to say, prostitutes, drug addicts, homosexuals; some practical tips to prevent AIDS, particularly in contacts with people; awareness about the basic precautions to take in case of accidental contact with those infected.

In support of this radio campaign, a public poster campaign without specific display plan is also driving. Three types of posters distributed or put up as events in hospitals and health centers and train stations, are developed by the same Health Education Service. The theme of these posters is about: the refusal of ignorance and denial of the disease, because no one is safe from AIDS. Knowledge is the best way to guard against infection. (AIDS is our enemy, all barons in his way; not die of ignorance; the more we know the better we avoid AIDS); the need not to participate in the spread of infection by an attitude of fidelity to the different sexual partners. ("Do not participate in the spread of AIDS," "Be faithful to one partner or the same partners in case of polygamy"); promoting the use of condoms as the only guarantee of non infection for any questionable sexual relationship. ("Love does not kill but AIDS kills" and at the foot of the same shows "we protect against AIDS, use condoms").

With the support of international donors, many awareness projects were designed and implemented in various regions of the country. In the area of Education, for example, we can cite:

a) The project to support the creation within some departments such as MINEDUC, of structures responsible for the fight against AIDS (Division of School Health, doctors personal assignment in this department);

b) The "creation of health clubs" in schools and United Nations Fund for financing training facilitators (UNICEF); 1993 Implementation year. 
c) The "training of peer educators" project in schools (high school students) in the province of the Far North, with funding from the international NGO "Save the Children". The NGOs also the training of peer educators for truckers, those of the Armed forces and the police in the same part of the country.

d) The "AIDS prevention in schools in Cameroon", initiated in 1990 with funding from the European Union. It aims to institutionalize an AIDS prevention program in the education system in Cameroon by the production of a textbook which should take into account all aspects Parent, teacher and youth, bring

e) Adolescents to play a role prevention officers within families, and rural or illiterate. The only tangible result today is the provision of an educational brochure on STD / AIDS.

In the agricultural sector, one of the most significant projects is the project "Operation driver STD/AIDS in rural areas," Assistant other components of the National Agricultural Extension Program (PNVA) became national extension program agricultural research (PNVRA). Until 1987 the committee against AIDS does not have within it a communication specialist to design and possibly organize and carry out campaigns. On the sidelines of the prevention campaign made radio and television spots, the medical world experts involved for their part in specialized programs of the national radio and national television for example to explain the scientific phenomenon of AIDS. Articles published in the local press yet continued to repeat that only the risk groups are affected by the disease. Considered the only "competent" to be reasonable about AIDS (it is a new disease that must be able to explain to people and help them to understand), but handicapped by the language too technical sector, personal medical world to legitimize their communication actions and value operated by recruiting allies in the media and well organized their different benefits. The media there were so associated that as vectors/ transmission belts between the world of "scholars" and that of "lay".

Moreover, as the Mpessa notes" "while actors in the fight to be heavily oriented towards the mass media as a major asset in the implementation of their communications, they have lost sight of that remedy has two handicaps major: media diversity is a handicap in the fight against AIDS; 'Événementialisation the' almost expected this appeal is itself the limits of the communication activities of the actors in the fight against AIDS."

But look for the theoretical framework of this discourse in the international context. In fact, the WHO multilateralism is coordinating the political action of states worldwide as corresponding to a speech that, in terms of international communication relations, comes in three axes recognizable: ${ }^{10}$ the discourse on the indivisibility (space, resources, challenges...); speech on the future (to improve the present, pre "adorn the future); Finally, universalism, which assumes equality and unity of men. This universalist humanism made this speech like all United Nations agencies' confused receptacle of all solicitations and all the vested interests involved in its universal vocation to accommodate political ". Although the national reception of international programs operates on the model of ownership of such programs, she and allowed to enter national recognition of angles, the communication perspective accuse debates and controversies structuring real territories meaning relatively stable and it can be set quite accurately. Thus one can interpret the skirmish and the outcry led by the Minister of Health about the various advertisements in the local press throughout the year 2004 on the ability of some traditional healers to cure AIDS. Communicational point of view accuses debates and controversies structuring real relatively stable sense of territory and it are possible to configure quite accurately. Thus one can interpret the skirmish and the outcry led by the Minister of Health about the various advertisements in the local press throughout the year 2004 on the ability of some traditional healers to cure AIDS. Communicational point of view accuses debates and controversies structuring real relatively stable sense of territory and it are possible to configure quite accurately. Thus one can interpret the skirmish and the outcry led by the Minister of Health about the various advertisements in the local press throughout the year 2004 on the ability of some traditional healers to cure AIDS.

During the months of January and February 2004, in fact, a 'Doctor' Dewah, traditional healer was published in the columns of La Nouvelle Expression, The Messenger and Mutations, a series of announcements relating his "achievements" in the management opportunistic infections and even AIDS. The announcements in the "front page" or "footer" in the inner pages (average size: $18.5 \mathrm{~cm} \times 12 \mathrm{~cm} / \mathrm{neck}$ ) invited the sick to visit for "all sexually transmitted infections including AIDS." Meanwhile the antennas of CRTV and some private radio stations in Yaoundé received in the interactive programs for people who claimed to "launch AIDS" or "cure AIDS". "I am convinced that people who talk a lot about AIDS are not happy that it disappears quickly because it is goodwill.

To which he replied Kaptue Lazarus, President of the Ethics Committee and the Committee set up by the Ministry of Health to assess the work of the former Minister of Health: "To my knowledge, whether in African or western pharmacopoeia, I do not know the AIDS cure" (Extract from interview in "positive living"). This scientific controversy has been to space for expression in the media added to the confused nature of the functions of these in the apprehension of the disease. What we think of ${ }^{11}$ analyzing the debates on public health, shows the effects of the expansion of scientific controversies pointing transformation of argument registers and modes of administration of proof when moving from the scientific journal on the news ${ }^{12}$ working on journalistic analysis of the debate on contaminated blood in France had meanwhile stressed the contrast between some media approaches that claimed to distancing, largely using the speech of scientists (biologists, epidemiologists) and others who are mingled more emotional registers (anger, accusation, etc.) the principle of the construction of the scandal, the mode of interaction between science, media and journalists perceive leaves no disciplinary or professional specificities but specific oppositions. Some write in their lexical grids that others interpret from their professional filters. Various lines of these discursive tensions can be distinguished in their impact on journalism. Thus, the paradox, the against-argumentation, refutation and above the central square of diglossia in the speeches of scientific and professional circles reflect the discursive tensions in the AIDS apprehension. A high variety of scientific lexicon (example: opaque formulas plain view but very satisfactory from the pragmatic point of view and the specific semantics each variety. But even within each variety, the scarcity of mixed fragments accuses the irreducible gap between AIDS tell of ways.

The contrast between statements depending on the social context (such as journalistic and communicational statements) and those who are part of the general rise in AIDS (scientific and policy statements). In this perspective, it is interesting to mention here the way journalists reflected in their speeches. The forms through which prior knowledge of specialists (associations, doctors), political (government) express AIDS, and the categories that they use to re-discuss them and to 
overcome them, beyond their media expression would have been a successful entry to understand how journalists are exempt media constraints to explain their positions. In particular the existence of professional networks (network of journalists on AIDS, networks of health journalists) reflects these movements of lines whose professional junctions serve as support.

\section{Thread: Back on the "dispersion" of journalistic knowledge}

Broadly, the voltage of journalism is not a new hypothesis. Many studies since the post-war show in both English speaking worlds that many changes affecting the media universe, so that some French researchers made journalism a privileged observation place of the mutation media landscape and even prophesied that it will maintain this position in the coming years. "We are defending that journalism was the site of onset of these changes and an alarm phrase towards the world of research," wrote Nicolas Pelissier and Francois Demers in 2014. In questioning particularly on the brakes and the barriers that have limited the development and influence of journalism in the academic field but also among professionals and society, the two authors already laid the beginnings of a real research program likely to switch attention to some disjunctive aspects of this profession better yet help nourish knowledge. Their purely heuristic contribution, however, allow Journalism Studies invest the field of reflection in which the various approaches intersect and open to fruitful controversy around the many paradigms that, closer to our perspective, the paradigm of paradoxical injunctions of the Ox and Pelissier seems one of the most original. Similarly, the notion of hyper-competition developed by ${ }^{13}$ like that of brand journalism from marketing, or public communication to the Canadian sense of discursive set of phenomena, including journalistic, development public already questioning the overhanging position of journalists with an audience of abstract citizens, but also in the African context, as an authority figure in the production of public speaking. The most significant trends of the various trade tensions are sometimes vertical and sometimes horizontal. Diversifying tools indeed create new opportunities that positively can be analyzed as an enrichment that allows the profession to reach the most diverse audiences by the most diversified means. But vertical upheaval of the order of speeches and professional hierarchies is one of the most significant consequences of these developments. In short, the voltage expressed here is not a suspended state and then it opens out according to the authors on an adaptation pacified situation and reclaiming (a); but at the same time questioning the direction of convergence and analyzed (b).

\section{The convergence of charms}

"In the digital age, writes Nicolas Pelissier this time with Mamadou Diallo Diouma, the wife of journalism elusive and multidimensional contours." The explanation for this indeterminacy is professional in finding "the instability of digital stratum and the difficulty to understand the range of practices within media organizations in their pluralistic approach to information and singular in their specificities". These authors cite the identity elasticity and plasticity of uses as a consequence of the influence of technology on journalism. But they insist that this is proof of the strong adaptability of professional backgrounds including through the reappropriation. "The fact that such journalism remains an open profession, whose territory variable geometry is allowed him to adapt repeatedly to different technological challenges it has faced in its history" They note. Many authors point including the connection of journalism with public relations as a fundamental variable in the convergence of journalism and communication practices. This convergence is first according to studies, technology; but it is also built by the two professional communities. technological convergence of all: as observed ${ }^{13}$ as a result of Manning ${ }^{13}$ journalistic information contains a high percentage of items designed by public relations" and in proportions ranging from 40 to $80 \%$ and which are growing with the acceleration of the rate of production of new and multiple platforms to be supplied. According to the author, part of the explanation lies in the technological changes that have imposed a widespread movement of convergence in the media industry since the 1990s ${ }^{14}$ this pushed journalists to develop new working methods to produce quickly in several platforms and at any time. Therefore, the boundaries between journalism and public relations as described by ${ }^{13}$ for the first sociopolitical legitimacy based on democratic values; and social influence and manipulation in the second were shaken, despite resistance from journalists. At the point that the issue of space autonomy of journalists may appear as central. Convergence then professionally built: based on semi-structured interviews with journalists from three Quebec daily, Le Journal de Montreal, La Presse and Le Devoir, Francoeur concludes that despite their words, the line between journalism and public relations is porous because of forced relationships that emphasize a limited flexibility and a narrow possibility of action of journalists, all entered three levels of apprehension: the functioning of public relations, the same culture of journalists and temporary alliances they are driven to spend with public relations. The study points to the fact that Canadian journalists, the mail is a preferred means of communication, part of the "game" and the public relations remains the quickest way to get factual information "real", that will not be challenged. They claim, however, have the final say on editorial decisions but their ethical obligations and production requirements come again restricted autonomy. They feel especially to team with public relations, an alliance with those who they feel empathy.

Despite its programmatic generosity, the concept of convergence has an important analytical weakness: the ability to standardize what is right together by professional ideologies, to unify what is distinct, and by this operation backed by the theorists, to eliminate uncertainty present in professional practice. The Millennium Project journalism, closely deterministic and messianic is less engaged and can hide the ambiguity of it. The opening of AIDS-related prevention activities to non-medical sectors shows in that respect the tense nature of journalistic awareness. A first opening process occurs as a result of a survey conducted in 1989 by the Organization for coordinating the fight against the major endemic diseases in Central Africa (OCEAC) with youth particularly in schools. This study establishes that this group had early sexual activity to be taken into account in defining target groups for awareness campaigns in the fight against AIDS. On this basis, and in collaboration with the Ministry of Education, a working group for the prevention of the fight against AIDS (sic) in schools is made.

\section{The risk of cross voltage}

If proximity journalism with public relations is emphasized and justified in studies, they are not the only communication practices whose proximity can be a source of conflict and for which the convergence is not a given to see. One can rest the question this notion of convergence since are highlighted points of tension both in practices and in the identities of the agents involved in the communicative system of AIDS. Three types of tension intersect: between journalism and public relations associations; between journalism and professional 
communication between journalism and media culture. If like Pelissier stresses et al. the arrival of the internet in media companies put the question of journalistic boundaries triple territorial level, reconfiguring and moving the boundaries of digital and porosity of the borders of journalism and business management online editorial content, convergence as a category to analyze the development crisis of journalism through communication seems unsatisfactory entry if it looks and reads as a solution to the problem studied. The growing weight of economic and technological constraints arises in effect at both ends of the convergence chain, to the point of a communications operator and a target voltage occurring even within the journalistic field. Also the context of AIDS he undertakes to deconstruct three types of assumptions: essentialist, first, leading to consider the media and journalism as united by a common destiny, then functionalist reducing communication data transmission and information, and finally showing the procedural contiguity or continuity of the working relationship between journalists and public relations and generally communicating. Seized process put rather light patterns on which it is legitimate to base the hypothesis of AC voltages. Journalists were interested in the subject AIDS as professional concern, however, point to the low weight of the communication of health care settings in the choice of subjects to the agenda. In their eyes, PR involved little in the field of health in general. As against the activism of "civil society AIDS" made on the occasion of the first International AIDS Conference (CISA) held in Yaounde is pointed as decisive in the structuring of the media discourse. But as noted Eboko" "Materials distributed in Cameroon like SidAlerte come from a continental or international Production, a detail that can pinpoint a feature of the first associations ... some active followership ... it seems that during the ten early years of the struggle against AIDS in Cameroon, local actors are 'satisfied' to reproduce the recipes of others. without trying to instill a specifically national impetus to their commitment.

It should be noted for example that coordination structure (ULS, NAC or GTC/CNLS) that produces very little - if at all - awareness materials during the 1984 campaign and the more sporadic the period $1986-1990$ (the funds at the time seemed to be lacking), it will provide associations awareness materials received various cooperation (WHO, UNFPA, UNICEF, French Cooperation/Project SUVY, GTZ/Health, USAID, SFPS, etc. Today there are over a hundred associations and organizations fighting against AIDS in Cameroon, 82 people living with HIV, established throughout the country, but still with a high concentration in the cities of Yaounde and Douala. Rest, The promotion of health, which is the central axis of communication strategies on AIDS aims to give people the means to ensure greater control over their own health. Now people living with HIV early felt a fear of social stigma, fear which later became a campaign argument to promote and claim their actions in communicating about AIDS. If this fear could be considered in the early campaigns, associations of people living with HIV have gradually become aware of the role that can be theirs in the National Program Management Fight against AIDS, and claimed status particular. In their logic, it was as if real expertise on AIDS could assert that through the experience of suffering. Criticism from infected people reports an attempt to exploit their position at their expense. If they must be an exhibition element for both the NAC as other organizations and associations that request them, they wish that their exhibitionism is beneficial because: "Who can better communicate on AIDS that the person who lives it? Membership in an association is not done (only) for the material profit. The most important is sharing "declared another HIV-positive member AFSU.

\section{Conclusion}

It is interesting to understand the relationship between journalism and communication from the perspective of the promotion but also the awareness of AIDS context for understanding the operation of two possible models tension underpinning these reports, namely the model protect the identity of the patient, on the one hand, and of the preservation of the social, on the other. Two irreconcilable models that protect one has long been an obstacle to the prosperity of the other and signed the boundaries of journalism. Two directions of theoretical interest for journalism tensions emerge from our study job strain dominant technocratic one hand. And cultural tension, resting it on the trust relationship with the company, on the other. Like any profession, journalism is built on a set of operations that originate from specialization of technical nature and prioritization of social practices based on the values of the Christian West. Symbols of the central conception of rationality, professions as practical and scholarly category at once. In the West combine the injunction to training, legitimizing groups and the passage of volunteering in wage labor, which are the central requirements. This positivist vision led to think journalism primarily as a method whose purpose could be summarized around a reporting requirement of the real to the public. But what is reality and how to prevent it will structure the nature of that report? What neutrality can claim the-record from the real account which he claims? However, the cultural tension, which suggests journalism as a product of a culture, would seek to emphasize the collective ritual character pointing the social issues of his accomplishment. ${ }^{15}$ this culturalist and constructivist design could be summarized by the statement that there is no practice of journalism that is not specific to a culture. In this perspective, Journalism is an activity designed primarily to promote discussion of implementation in social issues by maintaining a relationship of trust with the discussion the speakers in question mobilize and enhance the views. In this sense the rise of the paradigm of media coverage of the views of patients and families affected by AIDS is a step in the relationship of journalism to this pandemic. It demonstrates an interest for media reported receiving phenomena sick communities. In this sense the rise of the paradigm of media coverage of the views of patients and families affected by AIDS is a step in the relationship of journalism to this pandemic. It demonstrates an interest for media reported receiving phenomena sick communities. In this sense the rise of the paradigm of media coverage of the views of patients and families affected by AIDS is a step in the relationship of journalism to this pandemic. It demonstrates an interest for media reported receiving phenomena sick communities.

\section{Acknowledgments}

None.

\section{Conflicts of interest}

The author declares that there are no conflicts of interest.

\section{References}

1. Krieg Planque Alice. The concept of formula in discourse analysis. Theoretical and methodological Framework. Besançon: Presses Universitaires de Franche Comte; 2009. 145 p.

2. Babo Paul. History, diseases and medicine in West Africa-XXème nineteenth century. Journal History French Overseas. 1999;86(322323):237-268.

3. Boyomo Assala LC. When the genre seems. Little journalistic sociology 
of gender in Africa. In: Jean-Michel, Roselyn Uttard Ringoot, editors. The journalistic genres. Paris : Lharmattan; 2009.16 p.

4. Berlivet Luke. Deciphering the disease. Epidemiology and Public Health cultures. In: Dozon JP, Fassin D, editors. Public Health Cultures. Paris: Balland; 2002. 102 p.

5. Bernier Marc François. Journalists in the country of convergence. Serenity, discomfort and distress in the profession. Quebec: Laval University Presses; 2008.

6. Davis Aaron. Public Relations Democracy. Manchester: Manchester University Press; 2002. 222 p.

7. François Demers. The convergence as a new journalistic practice. In Marc François Bernier, François Demers, Alain Lavigne, et al, editors. Innovative Practices in Public Communication: Journalism, public relations and advertising. Quebec: Les Presses de 1'Université Laval; 2005. $105 \mathrm{p}$.

8. Eboko Fred. Health Identities, in Face to Face. 2004.

9. Etounou Tatiana, Mossus. Communication for Development (C4D) and paradigm shift in the fight against AIDS in Cameroon. Impact analysis bibliometric in evidence based policy making. In: Boyomo Assala, editor. Public Health, Faculty of Medicine and Biomedical Sciences, Cameroon: University of Yaounde; 2017. 19 p.
10. Francoeur Chantal. Convergence: how journalists' work revolves around communication, in French Review of Information Science and Communication. No. 10 Design and Transmedia: the crossing of SHS disciplines. 2017. $15 \mathrm{p}$.

11. Lochard, Guy, Boyer Henri. Media communication. Paris: Seuil; 1988. $250 \mathrm{p}$.

12. Manning Paul. The Press Association and News Agency Sources. In: Franklin B, editor. Newspapers Pulling Apart. London: Routledge; 2008. $304 \mathrm{p}$.

13. Mpessa Mouangue Marie-Marcelle. Thirty (30) years of communication and struggle against AIDS in Cameroon: set direction and staging of the institutional event. Information Sciences and Communication (SIC). University of Yaounde 2; 2014.

14. Nta Bitang to John. Cameroon Journalism: between profession and occupation; $2015.23 \mathrm{p}$.

15. Pelissier Nicolas, Demers François. Research on journalism. Know dispersed in the process of structuring in French Review of Information and communication Sciences. 2014;5:16. 